\title{
Short communication: Localization and expression of monocyte chemoattractant protein-1 in different subcutaneous and visceral adipose tissues of early-lactating dairy cows
}

\author{
S. Häussler, ${ }^{* 1}$ C. Sacré, ${ }^{*}$ K. Friedauer, ${ }^{*}$ S. Dänicke, $†$ and H. Sauerwein ${ }^{*}$ \\ *Institute of Animal Science, Physiology \& Hygiene Unit, University of Bonn, Katzenburgweg 7 - 9, 53115 Bonn, Germany \\ †Institute of Animal Nutrition, Friedrich-Loeffler-Institute (FLI), Federal Research Institute for Animal Health, 38116 Braunschweig, Germany
}

\begin{abstract}
The present study aimed to examine the mRNA abundance of the monocyte chemoattractant protein-1 (MCP-1) and to localize the MCP-1 protein in different subcutaneous (s.c.) and visceral (v.c.) fat depots in highyielding dairy cows. Early-lactating German Holstein cows $(\mathrm{n}=25)$ were divided into a control $(\mathrm{CON})$ and a conjugated linoleic acids (CLA)-supplemented group to investigate potential effects of dietary CLA treatment on MCP-1. The MCP-1 was localized in different s.c. and v.c. adipose tissue (AT) by immunohistochemistry, whereas the mRNA abundance was investigated using quantitative PCR. Albeit the infiltration of immune cells into bovine AT has been demonstrated to be only marginal, both MCP-1 protein and mRNA could be detected in bovine AT depots. The MCP-1 protein was localized both in the cytoplasm of adipocytes and in the cytoplasm of cells from the stromal vascular fraction; however, the number of MCP-1-positive cells was low. The mRNA abundances of MCP-1 were higher in v.c. compared with s.c. AT. Moreover, neither mRNA abundance nor protein expression of MCP-1 was seriously influenced by CLA supplementation of earlylactating dairy cows.
\end{abstract}

Key words: adipose tissue, dairy cows, monocyte chemoattractant protein-1

\section{Short Communication}

Early lactation is the most straining period for metabolism in high-yielding dairy cows. After calving, the energy requirements for milk synthesis cannot be covered by feed intake resulting in most cases in a state of negative energy balance (NEB). In response to NEB, high-yielding dairy cows mobilize lipids mainly from adipose tissue (AT), thus NEFA are released into the

Received December 18, 2014.

Accepted May 4, 2015.

${ }^{1}$ Corresponding author: susanne.haeussler@uni-bonn.de circulation (Herdt, 2000). Increased AT size in obese humans is positively associated with the expression of the monocyte chemoattractant protein-1 (MCP-1) (Christiansen et al., 2005). Besides its production by macrophages and endothelial cells, MCP-1 is synthesized by human preadipocytes and isolated mature adipocytes (Gerhardt et al., 2001). Furthermore, increasing fat mass is accompanied by macrophage infiltration into AT in obese humans and rodents, leading to a proinflammatory micromilieu, which may cause local and systemic insulin resistance (Weisberg et al., 2003; $\mathrm{Xu}$ et al., 2003). Obesity rarely occurs in dairy cows; however, massive mobilization of AT fat mass during the transition period from pregnancy to peak lactation is linked to a period of insulin resistance and reduced immune function (LeBlanc, 2010). However, lactationinduced metabolic alterations in early-lactating dairy cows were not accompanied by enhanced immune cell infiltration into AT (Akter et al., 2012).

Supplementation of diets with CLA, mainly the trans-10,cis-12 isomer, can reduce milk fat synthesis in dairy cows and thus attenuate NEB (Baumgard et al., 2002). In early lactation, CLA supplementation reduced adipocyte sizes from subcutaneous (s.c.) and visceral (v.c.) fat depots (Akter et al., 2011). Moreover, CLA can influence MCP-1 expression in human adipocytes; however, either inducing (Martinez et al., 2013) or inhibiting (McClelland et al., 2010) effects of CLA on MCP-1 in human adipocytes are reported.

Yet, to our knowledge, the expression of MCP-1 mRNA and protein in different AT depots of earlylactating dairy cows supplemented with or without CLA has not been investigated. Therefore, the objective of the present study was to examine the mRNA abundance of MCP-1 and localize the MCP-1 protein in different s.c. and v.c. AT depots in high-yielding dairy cows supplemented with or without CLA. The current experiment was approved by the Lower Saxony State Office for Consumer Protection and Food Safety (LAVES, Oldenburg, Germany). The experimental design has been described previously (von Soosten et al., 
2011). In brief, 25 primiparous German Holstein dairy cows with a mean BCS of $3.0 \pm 0.03$ (5-point scale; Edmonson et al., 1989) were housed in a freestall barn at the experimental station of the Institute of Animal Nutrition, Friedrich Loeffler-Institute (FLI, Braunschweig, Germany). Before parturition, the cows received a diet according to the recommendations of the German Society of Nutrition Physiology (GfE, 2001). The partial mixed ration contained $60 \%$ corn silage and $40 \%$ grass silage on a DM basis for ad libitum intake; $2 \mathrm{~kg}$ of concentrate per day in pelleted form were supplied by a computerized concentrate feeding station. After parturition, the animals were fed with a partial mixed ration consisting of $38 \%$ corn silage, $25 \%$ grass silage, and $37 \%$ concentrate on a DM basis. From 1 DIM until sample collection, animals were supplemented either with $100 \mathrm{~g} / \mathrm{d}$ of rumen-protected CLA (Lutrell Pure, BASF SE, Ludwigshafen, Germany; $\mathrm{n}=10$ ) or $100 \mathrm{~g} / \mathrm{d}$ of control fat supplement (CON; Silafat, BASF SE; n $=15)$. The CON cows $(\mathrm{n}=5$ each $)$ were slaughtered at 1,42 , and 105 DIM, whereas the CLA cows $(\mathrm{n}=5$ each) were slaughtered at 42 and 105 DIM. Immediately after slaughter, AT samples from 3 s.c. (tail head, withers, and sternum) and 3 v.c. (omental, mesenteric, and retroperitoneal) depots were collected, snap-frozen in liquid nitrogen, and stored at $-80^{\circ} \mathrm{C}$ until mRNA extraction. For histological analyses, samples were fixed in $4 \%$ paraformaldehyde (Roth, Karlsruhe, Germany) until further processing.

For the histological and immunohistological analyses, samples were dehydrated in ascending grades of isopropanol (Roth) and embedded in paraffin (Romeis, 2010). Bovine lymph nodes were collected from cows slaughtered at a local abattoir and served as control tissue. Immunohistochemistry on paraffin-embedded sections $(\mathrm{AT}=12 \mu \mathrm{m}$; lymph node $=6 \mu \mathrm{m})$ was performed as described previously (Häussler et al., 2013). Immunostaining was achieved by using a polyclonal antiserum raised in rabbits against bovine MCP-1/CCL2 (abnova PAB16914, Walnut, CA; 1:25 in PBS) incubated over night at room temperature (RT). Subsequently, biotinylated secondary antibodies raised in goats against rabbit IgG (Southern Biotech, Birmingham, AL, 1:200 in PBS, $30 \mathrm{~min}$ at RT), followed by incubation (30 min at RT) with horseradish peroxidase-labeled streptavidin (Southern Biotech; 1:1,000 in PBS), were used. Positive stainings were evaluated at 200-fold magnification using a Leica microscope (Leica DMR, Leica Microsystems, Wetzlar, Germany). Ten areas per section were randomly selected and evaluated using a grid $(350 \times 450$ $\mu \mathrm{m}$; DISKUS software, ver. 4, Hilgers, Königswinter, Germany). The number of positive cells per total cell number within the analyzed area was documented, and data were given as percentage of positive cells. Adipocyte areas $\left(\mu \mathrm{m}^{2}\right)$ from 100 adipocytes per each section were determined and reported previously (Akter et al., 2011).

Gene expression was quantified by quantitative PCR in all AT depots. Details of RNA extraction, purification, and quality control, cDNA synthesis, as well as quantitative PCR were described previously (Saremi et al., 2012). The following primers were used: MCP-1 (NM_174006.2, $171 \mathrm{bp}$ ) forward 5'-CAGCCAGATGCAATTAACTCCC-3', reverse 5'-CTGCTTGGGGTCTGCACATA-3'. The MCP-1 data were corrected based on PCR efficiency using amplicon standard curves. The amplicon standard curve was prepared from the purified PCR product with 10-fold dilution steps. The most stable reference genes in AT [i.e., LRP10 (low-density lipoprotein receptor-related protein 10), EIF3K (eukaryotic translation initiation factor 3, subunit K), and MARVELD1 (marvel domain containing 1)], were used to normalize the data (Saremi et al., 2012).

Statistical analyses were performed using SPSS (version 21.0, SPSS Inc., Chicago, IL). Data are presented as arithmetic means \pm standard error of the mean. Differences between DIM as well as between single AT depots were analyzed using the one-way ANOVA followed by Bonferroni post-hoc tests. Differences between CON and CLA cows were compared by the Student's $t$-test. Spearman correlation coefficients were calculated between the variables. Statistical significance was defined as $P \leq 0.05$.

Immunohistochemical analyses revealed that the MCP-1 protein was localized in the cytoplasm of adipocytes as well as in the cytoplasm of cells from the stromal vascular fraction in all AT depots (Figure 1). In general, the positive signal of the MCP-1 immunostaining was very weak and the percentage of MCP-1-positive cells detected in all AT samples was $0.94 \pm 0.56 \%$. The percentage of MCP-1-positive cells remained stable, either when comparing the single AT depots or the mean out of s.c. and v.c. AT depots. Moreover, no effect of the CLA supplementation on the percentage of MCP-1-positive cells was detected (Figure 2A). Comparing the lactation days, omental (2.4-fold) and mesenteric (4.3-fold) AT tended to be increased and s.c. AT from withers was 10-fold increased $(P=0.042)$ in CLA-treated cows on 42 compared with 105 DIM. In addition, the retroperitoneal AT tended to be increased 29-fold $(P=0.051)$ on 105 DIM compared with 42 DIM. Regarding the mRNA abundance of MCP-1 in different AT depots, the MCP-1 mRNA was 2.9- $(P<0.001)$ and 2.3 -times $(P<0.001)$ higher in v.c. than in s.c. AT on 1 DIM and on 42 and 105 DIM, 


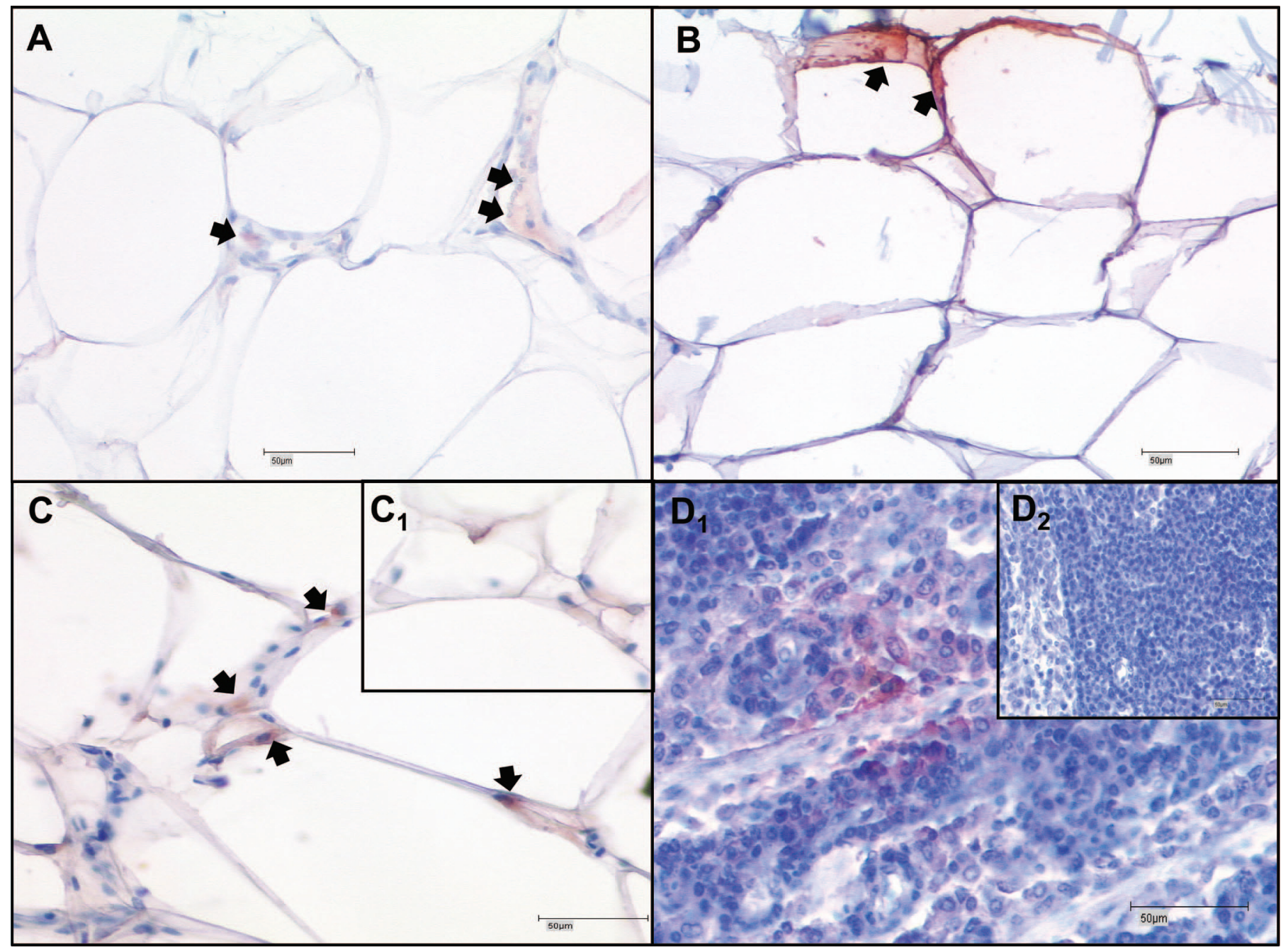

Figure 1. Examples of monocyte chemoattractant protein-1 (MCP-1) immunoreactivity in histological section from retroperitoneal fat located in the cytoplasm of adipocytes (A), omental fat (B), and subcutaneous fat from the tail head region (C) located in the cytoplasm of cells belonging to the stromal vascular cell fraction. Representative positive staining appear with reddish color and are marked with arrows. Bovine lymph nodes were used as positive $\left(D_{1}\right)$ and negative $\left(D_{2}\right)$ controls. For adipose tissue, a negative control without primary antibody was performed $\left(\mathrm{C}_{1}\right)$. Original magnification $=200$-fold; scale bars $=50 \mu \mathrm{m}$.

respectively (Figure 2D). Differences of MCP-1 mRNA between the single AT depots on 1, 42, and 105 DIM are presented in Figure 2B. Comparing the lactation days, at 1 DIM MCP-1 mRNA was expressed 3.4-fold $(P=0.033)$ more in retroperitoneal AT from $\mathrm{CON}$ cows than 105 DIM. In mesenteric AT, MCP-1 mRNA was increased 2.4-fold $(P=0.018)$ on 42 DIM of CON cows compared with 105 DIM. In response to inflammatory challenges, the adipokine MCP-1 recruits macrophages into AT (Kanda et al., 2006). However, immune cell infiltration was only marginal in AT samples from this study (as previously investigated by Akter et al., 2012). Albeit only few macrophages were detected in the AT samples investigated herein, slightly more macrophages were observed in v.c. than s.c. AT depots (Akter et al.,
2012). The higher MCP-1 mRNA abundance in v.c. AT depots might be related to an increased number of macrophages resident in v.c. AT (Bruun et al. 2005); however, immune cell infiltration into bovine AT has been shown to be of minor importance (Akter et al., 2012).

Anti-inflammatory effects of CLA, mainly through the cis-9,trans-11 isomer, were reported previously (Reynolds and Roche, 2010). In addition, supplementation with the cis-9,trans-11 isomer results in a decrease in inflammatory cytokines, which may improve insulin sensitivity in mice (Moloney et al., 2007). Therefore, we aimed to investigate the influence of dietary CLA supplementation on MCP-1 mRNA abundance and protein expression in different bovine AT depots. However, 

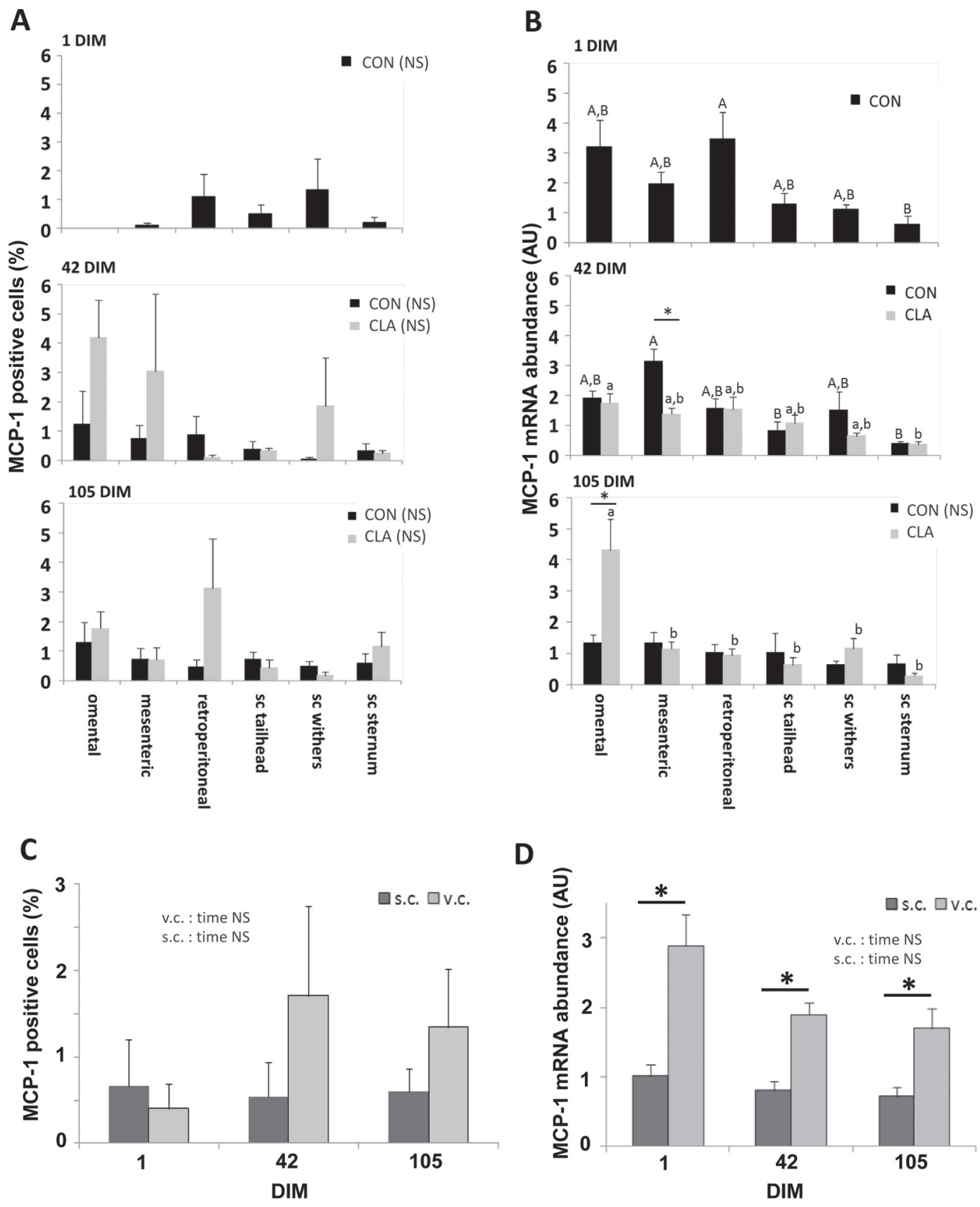

D

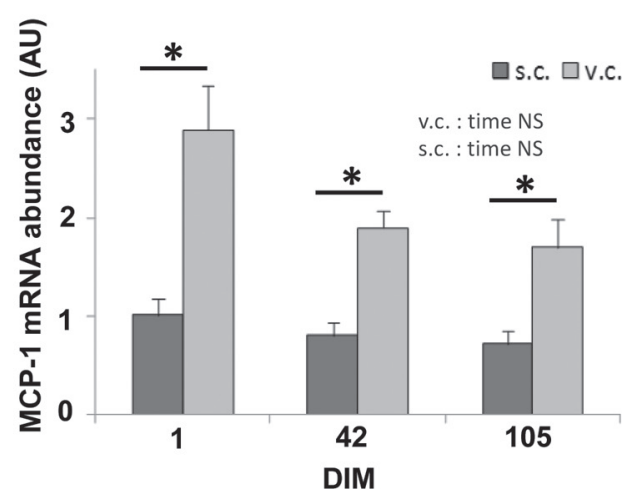

Figure 2. Portion (\%; mean \pm SEM) of monocyte chemoattractant protein-1 (MCP-1)-positive cells (A) and relative mRNA abundance (mean \pm SEM) of MCP-1 (B) in control $(\mathrm{CON})$ cows $(\mathrm{n}=15)$ and cows treated with CLA $(\mathrm{n}=10)$ on 1 , 42 , and 105 DIM in 6 different adipose tissue (AT) depots. Uppercase $(\mathrm{A}, \mathrm{B})$ and lowercase $(\mathrm{a}, \mathrm{b})$ letters indicate for differences between single AT depots in CON and CLA cows, respectively $(P \leq 0.05)$. Asterisks $\left(^{*}\right)$ in $\mathrm{A}$ and B indicate for differences between CON and CLA cows. (C) Portion (\%; mean \pm SEM) of MCP-1 positive cells and (D) relative MCP-1 mRNA abundance (means \pm SEM) in subcutaneous (s.c.) and visceral (v.c.) AT depots of cows irrespective of treatment on 1, 42, and 105 DIM. Asterisks $\left(^{*}\right)$ in D indicate differences between fat depots $(P \leq 0.05)$. AU $=$ arbitrary unit.

the marginal CLA effects observed in the present study were limited to undirected MCP-1 mRNA expression in 2 single AT depots in different DIM. Therefore, we propose that the CLA effects on MCP-1 were negligible, which might be due to low CLA amounts being detectable in the present AT samples (von Soosten et al., 2013).

Given that low concentrations of MCP-1 (1-100 pg/ $\mathrm{mL}$ ) were reported to stimulate AT angiogenesis through the vascular endothelial growth factor A (VEGFA; 
Parenti et al., 2004), we aimed to investigate the relationship between MCP-1 and the proangiogenic factor VEGFA as well as its receptor, VEGFR2. The mRNA abundances of VEGFA and VEGFR2 are presented in Supplemental Table S1 (http://dx.doi.org/10.3168/ jds.2014-9256). However, MCP-1 was only weakly correlated with VEGFA $(\mathrm{r}=0.297 ; P<0.001)$ and VEGFR2 $(\mathrm{r}=0.392 ; P<0.001)$, and the relationship was limited to the mRNA abundances. To elucidate direct effects of MCP-1 on angiogenic processes in bovine $\mathrm{AT}$, further investigations including the capacity of MCP-1 and blood vessel formation including cell culture studies should be performed.

Chemokines are secreted in response to signals such as pro-inflammatory cytokines; in particular MCP-1 is known as a potent chemotactic factor for monocytes (Deshmane et al., 2009). Besides its main expression by macrophages, the proinflammatory cytokine tumor necrosis factor (TNF)- $\alpha$ was expressed by cellfractionated AT and increased with obesity in rodents (Hotamisligil et al., 1993). In the present study, the relationship between $\mathrm{TNF}-\alpha$, which has been reported to be an adipokine produced by adipocytes (Hotamisligil et al., 1993), and MCP-1 was investigated in different AT depots. However, neither the number of positive MCP-1 cells nor the MCP-1 mRNA were related to TNF- $\alpha$ (TNF- $\alpha$ mRNA data were published by Saremi et al., 2014). Considering the v.c. and s.c. AT depots separately, TNF- $\alpha$ was weakly positively correlated with the mRNA abundance of MCP-1 in v.c. AT ( $\mathrm{r}=$ $0.286 ; P=0.014)$. The marginal associations observed in the present study point to a constitutive production of MCP-1 in AT, as suggested for various other cell types (Steube et al., 1999; Deshmane et al., 2009), rather than a simulation via cytokines.

In summary, although infiltration of immune cells into bovine AT has been demonstrated previously to be only marginal, the MCP-1 protein and MCP-1 mRNA were observed in s.c. and v.c. AT depots. Neither mRNA abundance nor protein expression of MCP-1 were influenced by CLA supplementation of early-lactating dairy cows.

\section{ACKNOWLEDGMENTS}

This research was funded by the German Research Foundation (DFG, Bonn, Germany, grant numbers: HA 6026/1-1 and PAK 286/1, SA 432/10-1). We thank K. Strack and I. Hofs (University of Bonn) for their excellent technical assistance. We acknowledge the support of I. Gockel-Böhner, S. Winand (Institute of Animal Science, University of Bonn), and the team from the Institute of Animal Nutrition and the experimental sta- tion of the Friedrich-Loeffler-Institute (FLI) in Braunschweig, Germany, for the support in sample collection.

\section{REFERENCES}

Akter, S. H., S. Häussler, S. Dänicke, U. Müller, D. von Soosten, J. Rehage, and H. Sauerwein. 2011. Physiological and conjugated linoleic acid-induced changes of adipocyte size in different fat depots of dairy cows during early lactation. J. Dairy Sci. 94:2871-2882.

Akter, S. H., S. Häussler, D. Germeroth, D. von Soosten, S. Dänicke, K.-H. Südekum, and H. Sauerwein. 2012. Immunohistochemical characterization of phagocytic immune cell infiltration into different adipose tissue depots of dairy cows during early lactation. J. Dairy Sci. 95:3032-3044.

Baumgard, L. H., B. A. Corl, D. A. Dwyer, and D. E. Bauman. 2002. Effects of conjugated linoleic acids (CLA) on tissue response to homeostatic signals and plasma variables associated with lipid metabolism in lactating dairy cows. J. Anim. Sci. 80:1285-1293.

Bruun, J. M., A. S. Lihn, S. B. Pedersen, and B. Richelsen. 2005 Monocyte chemoattractant protein-1 release is higher in visceral than subcutaneous human adipose tissue (AT): Implication of macrophages resident in the AT. J. Clin. Endocrinol. Metab. 90:2282-2289

Christiansen, T., B. Richelsen, and J. M. Bruun. 2005. Monocyte chemoattractant protein-1 is produced in isolated adipocytes, associated with adiposity and reduced after weight loss in morbid obese subjects. Int. J. Obes. (Lond.) 29:146-150.

Deshmane, S. L., S. Kremlev, S. Amini, and B. E. Sawaya. 2009 Monocyte chemoattractant protein-1 (MCP-1): An overview. J. Interferon Cytokine Res. 29:313-326.

Edmonson, A. J., I. J. Lean, L. D. Weaver, T. Farver, and G. Webster. 1989. A body condition scoring chart for Holstein dairy cows. J. Dairy Sci. 72:68-78.

Gerhardt, C. C., I. A. Romero, R. Cancello, L. Camoin, and A. D Strosberg. 2001. Chemokines control fat accumulation and leptin secretion by cultured human adipocytes. Mol. Cell. Endocrinol. 175:81-92.

GfE (Society of Nutrition Physiology). 2001. Ausschuss für Bedarfsnormen der Gesellschaft für Ernährungsphysiology. Nr. 8. Empfehlungen zur Energie- und Nährstoffversorgung der Milchkühe und Aufzuchtrinder (Recommendations of energy and nutrient supply for dairy cows and breeding cattle). DLG-Verlag, Frankfurt am Main, Germany.

Häussler, S., D. Germeroth, K. Friedauer, S. H. Akter, S. Dänicke, and H. Sauerwein. 2013. Characterization of the dynamics of fat cell turnover in different bovine adipose tissue depots. Res. Vet. Sci. 95:1142-1150

Herdt, T. H. 2000. Ruminant adaptation to negative energy balance. Influences on the etiology of ketosis and fatty liver. Vet. Clin. North Am. Food Anim. Pract. 16:215-230.

Hotamisligil, G. S., N. S. Shargill, and B. M. Spiegelmann. 1993. Adipose expression of tumor necrosis factor-alpha: Direct role in obesity-linked insulin resistance. Science 259:87-91.

Kanda, H., S. Tateya, Y. Tamori, K. Kotani, K. Hiasa, R. Kitazawa, S. Kitazawa, H. Miyachi, S. Maeda, K. Egashira, and M. Kasuga. 2006. MCP-1 contributes to macrophage infiltration into adipose tissue, insulin resistance, and hepatic steatosis in obesity. J. Clin. Invest. 116:1494-1505.

LeBlanc, S. 2010. Monitoring metabolic health of dairy cattle in the transition period. J. Reprod. Dev. 56(Suppl):S29-S35.

Martinez, K., S. Shyamasundar, A. Kennedy, C. C. Chuang, A. Marsh, J. Kincaid, T. Reid, and M. McIntosh. 2013. Diacylglycerol kinase inhibitor R59022 attenuates conjugated linoleic acid-mediated inflammation in human adipocytes. J. Lipid Res. 54:662-670.

McClelland, S., C. Cox, R. O' Connor, M. de Gaetano, C. McCarthy, L. Cryan, D. Fitzgerald, and O. Belton. 2010. Conjugated linoleic acid suppresses the migratory and inflammatory phenotype of the monocyte/macrophage cell. Atherosclerosis 211:96-102. 
Moloney, F., S. Toomey, E. Noone, A. Nugent, B. Allan, C. E. Loscher, and H. M. Roche. 2007. Antidiabetic effects of cis-9,trans-11-conjugated linoleic acid may be mediated via anti-inflammatory effects in white adipose tissue. Diabetes 56:574-582.

Parenti, A., L. Bellik, L. Brogelli, S. Filippi, and F. Ledda. 2004. Endogenous VEGF-A is responsible for mitogenic effects of MCP1 on vascular smooth muscle cells. Am. J. Physiol. Heart Circ. Physiol. 286:H1978-H1984.

Reynolds, C. M., and H. M. Roche. 2010. Conjugated linoleic acid and inflammatory cell signalling. Prostaglandins Leukot. Essent. Fat. Acids 82:199-204.

Romeis, B. 2010. Mikroskopische Technik. 18th ed. M. Mulisch and U. Welsch, ed. Sepktrum Akademischer Verlag, Heidelberg, Germany.

Saremi, B., H. Sauerwein, S. Dänicke, and M. Mielenz. 2012. Technical note: Identification of reference genes for gene expression studies in different bovine tissues focusing on different fat depots. J. Dairy Sci. 95:3131-3138.

Saremi, B., S. Winand, P. Friedrichs, A. Kinoshita, J. Rehage, S. Dänicke, S. Häussler, G. Breves, M. Mielenz, and H. Sauerwein. 2014. Longitudinal profiling of the tissue-specific expression of genes re- lated with insulin sensitivity in dairy cows during lactation focusing on different fat depots. PLoS ONE 9:386211.

Steube, K. G., C. Meyer, and H. G. Drexler. 1999. Constitutive protein expression of monocyte chemotactic protein-1 (MCP-1) by myelomonocytic cell lines and regulation of the secretion by anti- and proinflammatory stimuli. Leuk. Res. 23:843-849.

von Soosten, D., R. Kramer, G. Jahreis, U. Meyer, G. Flachowsky, and S. Dänicke. 2013. Transfer of conjugated linoleic acids into different tissues of dairy cows. Arch. Anim. Nutr. 67:119-133.

von Soosten, D., U. Meyer, E. Weber, J. Rehage, G. Flachowsky, and S. Dänicke. 2011. Effect of trans-10,cis-12 conjugated linoleic acid on performance, adipose depot weights, and liver weight in earlylactation dairy cows. J. Dairy Sci. 94:2859-2870.

Weisberg, S. P., D. McCann, M. Desai, M. Rosenbaum, R. L. Leibel, and A. W. Ferrante. 2003. Obesity is associated with macrophage accumulation in adipose tissue. J. Clin. Invest. 112:1796-1808.

Xu, H., G. T. Barnes, Q. Yang, G. Tan, D. Yang, C. J. Chou, J. Sole, A. Nichols, J. S. Ross, L. A. Tartaglia, and H. Chen. 2003. Chronic inflammation in fat plays a crucial role in the development of obesity-related insulin resistance. J. Clin. Invest. 112:1821-1830. 